\title{
Review
}

\section{Clinical Pain Assessment Scoring Systems and Practice Essentials in Acute and Chronic Pain}

\author{
Ahmed Abdelhady ${ }^{1}$, Rawan Alshahrani ${ }^{2}$, Rawabi Asaheimi ${ }^{3}$, Amani Alamrani ${ }^{4}$, Mohammed Alqahtani ${ }^{2}$, Abdulelah \\ Asiri $^{2}$, Yousef Alharthi ${ }^{5}$, Aseel Alnamlah ${ }^{6}$, Abdulallah Mguens ${ }^{7}$, Fatimah Al Tarouti ${ }^{8}$, Zeinab AlHawsawi ${ }^{9}$ \\ ${ }^{1}$ Department of Emergency Medicine, East Jeddah Hospital, Jeddah, Saudi Arabia \\ ${ }^{2}$ College of Medicine, King Khalid University, Abha, Saudi Arabia \\ ${ }^{3}$ College of Medicine, Jouf University, Al-Jouf, Saudi Arabia \\ ${ }^{4}$ Department of Emergency Medicine, King Abdulaziz Hospital, Jeddah, Saudi Arabia \\ ${ }^{5}$ College of Medicine, Tabuk University, Tabuk, Saudi Arabia \\ ${ }^{6}$ College of Medicine, Princess Nourah Bint Abdul Rahman University, Riyadh, Saudi Arabia \\ ${ }^{7}$ College of Medicine, Medical University of Lodz, Lodz, Poland \\ ${ }^{8}$ Department of Emergency Medicine, Jubail General Hospital, Jubail, Saudi Arabia \\ ${ }^{9}$ College of Medicine, Ibn Sina National College, Jeddah, Saudi Arabia
}

Correspondence should be addressed to Ahmed Abdelhady, Department of Emergency Medicine, East Jeddah Hospital, Jeddah, Saudi Arabia, email: ahmedesmae1500@gmail.com

Received 30 May 2021; Revised 5 June 2021; Accepted 7 June 2021; Published 16 June 2021

Copyright (C) 2021 Abdelhady et al. This is an open access article distributed under the Creative Commons Attribution License, which permits unrestricted use, distribution, and reproduction in any medium, provided the original work is properly cited.

\begin{abstract}
Pain is the most common symptom patients complain from in the emergency setting. Due to the significant dependence on the management modality of pain, and the highly increasing cultural myths about pain, it is essential to evaluate and diagnose the characteristics of pain as early and correctly as possible. Many assessment modalities for pain have been previously proposed in clinical settings and research studies. In this review, we will report significant evidence about the assessment tools for the acute and chronic pain, together with the reported practice essentials. Assessment tools have been divided in this paper based on the different aspects of pain, associated morbidities, and concurrent effects. Finally, discussion related to the clinical guidelines and assessment tools for the evaluation of pain in pediatric settings and the most suitable approaches to achieve a proper diagnosis is reported. This includes previous investigations that have reported the Revised Face, Legs, Activity, Cry, Consol ability (r-FLACC) and the Individualized Numeric Rating Scale (INRS) can be effectively used in emergency and healthcare pain assessment situations and also in settings where children usually present with atypical presentations and symptoms. Other detailed approaches and scoring systems are discussed within the study.
\end{abstract}

Keywords: Pain; assessment; scoring systems; clinical, emergency medicine 
Journal of Healthcare Sciences

\section{Introduction}

Pain is the most common symptom patients complain from in the emergency and healthcare setting. Previous estimates from the United States show that approximately $20 \%$ of the American population suffers from chronic pain (1). Chronic pain prevalence is usually higher in the geriatric group (2). Assessment of pain can be a simple or complex procedure, and clinicians are encouraged to approach the patient systematically to obtain a better diagnosis and evaluation. A common approach is to differentiate between chronic and acute pain, however, with the increasing prevalence of analgesics and Opioids administration, it is becoming increasingly difficult to properly diagnose pain. Moreover, early assessment of pain is essential, because chronic pain can significantly affect the physical function, emotional status, and the affected patients' quality of life. A previous estimate indicated that approximately $6 \%$ of children and $8 \%$ of adults suffer from chronic pain-induced limitations of daily physical activities and quality of life $(1,3)$.

Furthermore, due to the significant dependence on the management modality of pain, and the highly increasing cultural myths regarding pain, it is essential to evaluate and diagnose the characteristics of pain as early and correctly as possible $(4,5)$. Many assessment modalities for pain have been previously proposed in clinical settings and research studies. In this review, we will formulate current significant evidence regarding the assessment tools utilized for acute and chronic pain, together with the reported practice essentials.

\section{Assessment of Intensity, Quality, and Location}

Many scoring systems have been developed and validated for the assessment of chronic pain. Standardized assessment tools for pain assessment have been previously reported for many purposes, including the assessment of chronic pain quality and location, pain intensity, interference with functions and quality of life, overt expressions of pain, and emotional distress and

coping. For assessment of pain intensity, self-rating Figure 1. Assessment of pain using the VAS, VRS, and NRS assessment tools are the most suitable in situations where (13).

patients are asked to rate their pain generally and in a simple way.
Numerical Rating Scales (NRS) are the most commonly reported assessment tools for this purpose and are utilized by asking the patients to rate pain intensity from 0-10 based on the severity of their pain, where 0 equals no pain and 10 equals the most intense pain that they can imagine (6). Verbal Rating Scales (VRS) are also a common chronic pain assessment modalities that ask the patient to assess the intensity of pain using their own words to classify their current pain as mild, moderate, or severe (7).

Previous investigations have reported the reliability and validity of both scoring systems (8), however, some differences were also noted as worthy of consideration by future investigations. Issues that should be considered when considering either assessment modalities include failing to complete the measures, missing data, patient preference, being able to complete the measures by telephone or other methods, and the ability to record data easily $(8,9)$. For instance, cases where NRS cannot be completed, VRS can be easily used instead, and vice versa, in patients suffering from language impairment. Using diaries for recording chronic pain scores is a favorable habit that has gained great acceptance, as opposed to asking patients to recall the intensity of their pain (10). Other reported tools include the Visual Analog Scale (VAS), the Facial Pain Scale, and the Iowa pain Thermometer, which have all been previously validated and are commonly used in clinical settings and relevant research studies $(8,11,12)$. Figure 1 shows a summary of pain assessment using the VAS, NRS, and VRS.

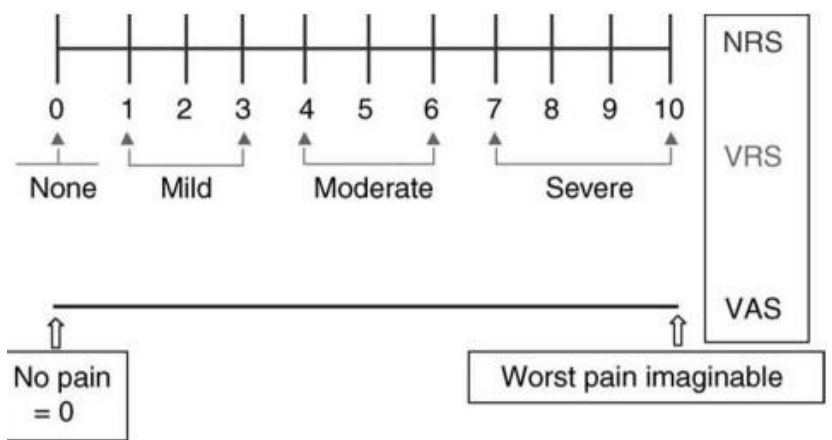


Assessing the quality and location of the pain is also important for pain evaluation and appropriate management. For instance, pain characteristics such as stabbing or scratching may aid in the correct identification of the pain etiology, as they can provide clues that aid an accurate diagnosis. The use of simple pain drawings of the human body can help patients easily identify the location of the pain by indicating the site where the pain is felt on a diagram of the human body (14).

The McGill Pain Questionnaire (MPQ) was previously reported as a valid tool for this purpose that can be used to assess the affective, sensory, and evaluative qualities of pain (15). Following the assessment of this tool, it was further revised and modified to the Short-Form McGill Pain Questionnaire 2 (SF-MPQ-2) version which was favourably accepted by clinical practitioners (16, 17).The Neuropathic Pain Scale (NPS) and Rainbow Pain Scale (RPS) were also assessed for similar purposes and are utilized in the healthcare settings $(14,18)$.

\section{Assessment of the Physical Functions and Quality of Life}

Many scoring systems and measures have been previously proposed for acute and chronic pain assessment for different age groups. Common abbreviations are clinically used by clinicians such as "OLDCARTS" and "COLDERAS" which they were developed for accurate estimation of pain and to effectively describe onset, duration, character, relieving symptoms, associated symptoms, the severity of symptoms, and pain radiation (19).

When clinicians follow a specific scoring systems, it is possible to conduct a multidimensional assessment of the characteristics of pain and its severity to properly help the affected patients. The Pain, Enjoyment of Life and General Activity Scale (PEG) was previously reported to effectively assess acute pain, with the main characteristics of the tool assessing the quality of life and physical functions of the affected patients (20). The PEG is graded from 0-10 based on the included and assessed categories, and higher scores indicate minimal functions and more severe pain. For example, if an individual with chronic pain is assessed as having a PEG score of $7 / 10$, the patient is then treated with both pharmacological and non-pharmacological management modalities.
After initiating the treatment, the score should be observed as declining, indicating that the physical functions and the quality of life for these patients has improved (20).

Chronic pain can significantly impact the quality of life for the affected patients and can interfere with their daily performance of routine activities. Accordingly, assessment of the physical functions of patients suffering from chronic pain should be recommended for all patients to enhance their prognosis and maintain adequate management $(21,22)$. However, the tools that were initially designed for this purpose were poor and not reliable, making patients self-report their functional status and describe their symptoms for adequate evaluation of their conditions. Studies have suggested that in clinical settings, it is essential to assess and properly evaluate the health-related quality of life (HRQOL).

In this context, many previous investigations have evaluated surveys and procedures that can help assess the HRQOL for patients with chronic pain $(23,24)$. Some of the proposed measures include a SF-36 survey, which is a set of short questions that assess the outcome and quality of life in addition to the reported general measures and surveys. Some of those tools aim to assess physical functions such as the Pain Disability Index (PDI) while others measure disease-specific pain such as Roland-Morris Disability Questionnaire (RDQ) for low back pain and The Western Ontario and McMaster Universities Osteoarthritis Index (WOMAC) for osteoarthritic pain (25-28).

The usefulness of these measures becomes clear when generic approaches are not able to quantify the assessment of pain regarding specific effects which can only be detected by using the disease-specific approaches. Accordingly, combining both general and specific measures can significantly improve the quality of pain assessment and obtain better evaluation and diagnostic outcomes.

\section{Assessment of Coping, Emotional Distress and Overt Expression}

Previous studies have reported many scoring systems for the assessment of the emotional status of patients suffering from both acute and chronic pain. Among the proposed modalities, the four-item Patient Health 
Questionnaire (PHQ-4) has been previously validated, and is a combined form of the Patient Health Questionnaire-9 (PHQ9) and the General Anxiety Disorder-7 (GAD7) tools for assessment of emotional distress symptoms in patients suffering from pain (29). It has been suggested that assessment of patients with chronic pain should be undertaken using the PHQ-4 scoring system, and if the patient recorded a score of more than 5, a full assessment of these cases using the PHQ-9, GAD-7, and the Primary Care Post Traumatic Stress Disorder (PTSD) screening measures should be undertaken (30). Another assessment tool is the Defense and Veterans Pain Rating Scale (DVRPS), which assesses the effect of pain on mood, sleep, daily activities, and stress (31). The DVRPS is a five-item tool that is graded from $0-10$, and higher scores indicate a higher severity of pain.

Assessment of the emotional status of patients suffering from chronic pain is also essential as previous studies have reported that these patients may suffer from emotional symptoms including anxiety, stress, depression and irritability $(32,33)$. The development and initial presentation of patients with chronic pain with emotional symptoms can represent a significant challenge that may mask the appropriate diagnosis and evaluation of pain. It can result from fatigue, appetite change, weight gain, libido changes, sleep disturbances, decreased levels of activities and concentration and memory deficits. These symptoms may be originally attributable to the emotional status and conditions of these patients. For assessment of these cases, previous investigations have reported the validation of specific tools that were designed to evaluate the impact of pain on the patients' quality of life, emotional distress, feelings of control, and the attitude of the patient towards their disease, healthcare providers and pain, in addition to the secondary coping behaviors that have been developed by these patients (34).

The Profile of Mood States (POMS) and the Beck Depression Inventory (BDI) have been previously validated as tools for the psychometrical assessment of patients with chronic pain (35-37). However, it has been recommended that the results of these scoring systems should be carefully interpreted as some modifications must be induced to accurately obtain proper findings (38). Overt expression of pain was also previously reported among studies in the literature, as some pain may be assessed verbally whilst some painful effects are better expressed by non-verbal bodily expressions that may better exhibit the distress, the experience of pain, or suffering (39). Many advantages have been observed secondary to using these behavioral measures, including well-established communicative advantages with the corresponding healthcare providers and the provision of advantages for the patients and their healthcare givers about the potential prognosis of their pain. For instance, the Pain Behaviour Checklist (PBC) is commonly described in clinical settings for the assessment of painrelated behaviors (40). Full history taking from the patient may also be of clinical significance in the assessment of the behavioral changes that can be present in patients with chronic pain.

\section{Assessment of Pain in Pediatric Patients}

In pediatric settings, observational scales are used to assess the behaviors of patients suffering from pain. Using visual analogs in these settings is a common and effective practice, and facial expressions are used with pictures to help in the assessment of the various degrees of pain (41). Previous studies have also demonstrated that, as children grow up through adolescence, they can effectively rate their degree of pain using a numerical assessment tool and selfreporting modalities, similar to adults (42). The Pediatric Pain Questionnaire and the Adolescent and Pediatric Pain assessment measure have been reported as an effective modality for children that are 10 years old (43). The tool is generally utilized by asking children to draw a body map that identifies the location of their pain. In cases where patients are not able to express or selfreport their pain, observations of the distractibility, facial expressions, and fussiness can help in establishing a proper diagnosis and adequate evaluation of the pain. For this purpose, the Revised Face, Legs, Activity, Cry, Consol ability (r-FLACC) tool has been described as an effective observational measure that can help clinicians measure pain in a pediatric setting $(41,44,45)$. The Nursing Assessment of Pain Intensity (NAPI) tool was also reported as an efficacious modality for assessing pain in pediatric patients (46). Due to their reported success in assessing pain, both r-FLACC and NAPI tools remain the most efficacious and commonly used (44, 47-49). Lastly, neurological impairment can represent a challenge for clinicians when approaching pain assessment in the pediatric setting. Previous investigations have reported that the r-FLACC and the Individualized Numeric Rating Scale (INRS) can be effectively used in these situations and also in situations where children present with atypical presentations and symptoms $(48,50)$. 
Journal of Healthcare Sciences

presentations and symptoms (48, 50). Limitation of this study is that no reported outcomes have been mentioned as this aims to give a general overview on best ways to approach the pain and assess. Furthermore, choosing a specific pain scale was based on personal opinion of the authors. We recommend future studies to compare pain scales on a multi-center level.

\section{Conclusion}

Pain tools can be divided based on the different aspects of pain, associated morbidities and concurrent effects. Using and combining pain scales according to each clinical situation is proven to be most efficient in utilizing these tools efficiently. Regardless of which age group the patient belongs to, the most crucial part is choosing the correct pain scale and applying it to help assess the pain level and help relief the pain accordingly.

\section{Acknowledgement:}

The authors would like to thank the ministry of health of Saudi Arabia for providing the necessary access and guideline in making of this review.

\section{Disclosure:}

\section{Statement:}

The authors declare that there is no conflict of interest.

\section{Funding:}

None

\section{Ethical consideration:}

None applicable

\section{References}

1. Dahlhamer J, Lucas J, Zelaya C, Nahin R, Mackey S, DeBar L, et al. Prevalence of Chronic Pain and High-Impact Chronic Pain Among Adults - United States, 2016. MMWR Morbidity and mortality weekly report. 2018;67(36):1001-6.

2. Johannes CB, Le TK, Zhou X, Johnston JA, Dworkin RH. The prevalence of chronic pain in United States adults: results of an Internet-based survey. The journal of pain. 2010;11(11):1230-9.

3. Tumin D, Drees D, Miller R, Wrona S, Hayes D, Jr., Tobias JD, et al. Health Care Utilization and
Costs Associated With Pediatric Chronic Pain. The journal of pain. 2018;19(9):973-82.

4. Generaal E, Vogelzangs N, Macfarlane GJ, Geenen R, Smit JH, de Geus EJ, et al. Biological Stress Systems, Adverse Life Events, and the Improvement of Chronic Multisite Musculoskeletal Pain Across a 6-Year Follow-Up. The journal of pain. 2017;18(2):155-65.

5. Bouhassira D, Lantéri-Minet M, Attal N, Laurent B, Touboul C. Prevalence of chronic pain with neuropathic characteristics in the general population. Pain. 2008;136(3):380-7.

6. Price DD, Bush FM, Long S, Harkins SW. A comparison of pain measurement characteristics of mechanical visual analogue and simple numerical rating scales. Pain. 1994;56(2):217-26.

7. Jensen MP, Karoly P, Braver S. The measurement of clinical pain intensity: a comparison of six methods. Pain. 1986;27(1):117-26.

8. Jensen M, Karoly P, Turk D, Melzack R. Handbook of pain assessment. Londres: Guilford. 2001.

9. Closs SJ, Barr B, Briggs M, Cash K, Seers K. A comparison of five pain assessment scales for nursing home residents with varying degrees of cognitive impairment. Journal of pain and symptom management. 2004;27(3):196-205.

10. Stone AA, Shiffman S. Capturing momentary, self-report data: a proposal for reporting guidelines. Annals of behavioral medicine : a publication of the Society of Behavioral Medicine. 2002;24(3):236-43.

11. Bieri D, Reeve RA, Champion DG, Addicoat L, Ziegler JB. The Faces Pain Scale for the selfassessment of the severity of pain experienced by children: development, initial validation, and preliminary investigation for ratio scale properties. Pain. 1990;41(2):139-50.

12. Herr K, Spratt KF, Garand L, Li L. Evaluation of the Iowa pain thermometer and other selected pain intensity scales in younger and older adult cohorts using controlled clinical pain: a preliminary study. Pain medicine (Malden, Mass). 2007;8(7):585- 


\section{Journal of Healthcare Sciences}

600.

13. Breivik H, Borchgrevink PC, Allen SM, Rosseland LA, Romundstad L, Breivik Hals EK, et al. Assessment of pain. British Journal of Anaesthesia. 2008;101(1):17-24.

14. Wolfe F. Pain extent and diagnosis: development and validation of the regional pain scale in 12,799 patients with rheumatic disease. The Journal of rheumatology. 2003;30(2):369-78.

15. Melzack R. The McGill Pain Questionnaire: major properties and scoring methods. Pain. 1975;1(3):277-99.

16. Dworkin RH, Turk DC, Revicki DA, Harding G, Coyne KS, Peirce-Sandner S, et al. Development and initial validation of an expanded and revised version of the Short-form McGill Pain Questionnaire (SF-MPQ-2). Pain. 2009;144(12):35-42.

17. Piotrowski C. Assessment of pain: a survey of practicing clinicians. Perceptual and motor skills. 1998;86(1):181-2.

18. Galer BS, Jensen MP. Development and preliminary validation of a pain measure specific to neuropathic pain: the Neuropathic Pain Scale. Neurology. 1997;48(2):332-8.

19. Dydyk AM, Grandhe S. Pain Assessment. StatPearls [Internet]. 2020.

20. Krebs EE, Lorenz KA, Bair MJ, Damush TM, Wu J, Sutherland JM, et al. Development and initial validation of the PEG, a three-item scale assessing pain intensity and interference. Journal of general internal medicine. 2009;24(6):733-8.

21. Turk DC, Dworkin RH, Revicki D, Harding G, Burke LB, Cella D, et al. Identifying important outcome domains for chronic pain clinical trials: an IMMPACT survey of people with pain. Pain. 2008;137(2):276-85.

22. Turk DC, Dworkin RH, Allen RR, Bellamy N, Brandenburg N, Carr DB, et al. Core outcome domains for chronic pain clinical trials: IMMPACT recommendations. Pain. 2003;106(3):337-45.
23. Gladman DD, Mease PJ, Strand V, Healy P, Helliwell PS, Fitzgerald O, et al. Consensus on a core set of domains for psoriatic arthritis. The Journal of rheumatology. 2007;34(5):1167-70.

24. Salaffi F, Sarzi-Puttini P, Ciapetti A, Atzeni F. Assessment instruments for patients with fibromyalgia: properties, applications and interpretation. Clinical and experimental rheumatology. 2009;27(5 Suppl 56):S92-105.

25. Ware JE, Jr., Sherbourne CD. The MOS 36-item short-form health survey (SF-36). I. Conceptual framework and item selection. Medical care. 1992;30(6):473-83.

26. Pollard CA. Preliminary validity study of the pain disability index. Perceptual and motor skills. 1984;59(3):974.

27. Bellamy N, Buchanan WW, Goldsmith $\mathrm{CH}$, Campbell J, Stitt LW. Validation study of WOMAC: a he.alth status instrument for measuring clinically important patient relevant outcomes to antirheumatic drug therapy in patients with osteoarthritis of the hip or knee. The Journal of rheumatology. 1988;15(12):1833-40.

28. Roland M, Morris R. A study of the natural history of back pain. Part I: development of a reliable and sensitive measure of disability in low-back pain. Spine. 1983;8(2):141-4.

29. Kroenke K, Spitzer RL, Williams JB, Löwe B. An ultra-brief screening scale for anxiety and depression: the PHQ-4. Psychosomatics. 2009;50(6):613-21.

30. Prins A, Bovin MJ, Smolenski DJ, Marx BP, Kimerling R, Jenkins-Guarnieri MA, et al. The Primary Care PTSD Screen for DSM-5 (PCPTSD-5): Development and Evaluation Within a Veteran Primary Care Sample. Journal of general internal medicine. 2016;31(10):1206-11.

31. Polomano RC, Galloway KT, Kent ML, BrandonEdwards $\mathrm{H}$, Kwon $\mathrm{KN}$, Morales $\mathrm{C}$, et al. Psychometric Testing of the Defense and Veterans Pain Rating Scale (DVPRS): A New Pain Scale for Military Population. Pain medicine (Malden, Mass). 2016;17(8):1505-19. 
Journal of Healthcare Sciences

32. Turk DC, Okifuji A. Psychological factors in chronic pain: evolution and revolution. Journal of consulting and clinical psychology. 2002;70(3):678-90.

33. McBeth J, Macfarlane GJ, Benjamin S, Silman AJ. Features of somatization predict the onset of chronic widespread pain: results of a large population-based study. Arthritis and rheumatism. 2001;44(4):940-6.

34. Turk DC, Melzack R. Handbook of pain assessment: Guilford Press; 2011.

35. Dworkin RH, Turk DC, Wyrwich KW, Beaton D, Cleeland CS, Farrar JT, et al. Interpreting the clinical importance of treatment outcomes in chronic pain clinical trials: IMMPACT recommendations. The journal of pain. 2008;9(2):105-21.

36. McNair DM. Profile of mood states. Educational and Industrial Testing Service. 1992.

37. Beck AT, Ward CH, Mendelson M, Mock J, Erbaugh J. An inventory for measuring depression. Archives of general psychiatry. 1961;4:561-71.

38. Turk DC, Okifuji A. Detecting depression in chronic pain patients: adequacy of self-reports. Behaviour research and therapy. 1994;32(1):9-16.

39. Keefe FJ, Dunsmore J, Burnett R. Behavioral and cognitive-behavioral approaches to chronic pain: recent advances and future directions. Journal of consulting and clinical psychology. 1992;60(4):528-36.

40. Richards SJ, Nepomuceno C, Riles M, Suer Z. Assessing pain behavior: the UAB Pain Behavior Scale. Pain. 1982;14(4):393-8.

41. Friedrichsdorf SJ, Giordano J, Desai Dakoji K, Warmuth A, Daughtry C, Schulz CA. Chronic Pain in Children and Adolescents: Diagnosis and Treatment of Primary Pain Disorders in Head, Abdomen, Muscles and Joints. Children (Basel, Switzerland). 2016;3(4).
42. Beyer JE, Denyes MJ, Villarruel AM. The creation, validation, and continuing development of the Oucher: a measure of pain intensity in children. Journal of pediatric nursing. 1992;7(5):335-46.

43. Tomlinson D, von Baeyer CL, Stinson JN, Sung L. A systematic review of faces scales for the selfreport of pain intensity in children. Pediatrics. 2010;126(5):e1168-98.

44. Breau LM, Camfield C, McGrath PJ, Rosmus C, Finley GA. Measuring pain accurately in children with cognitive impairments: refinement of a caregiver scale. The Journal of pediatrics. 2001;138(5):721-7.

45. Malviya S, Voepel-Lewis T, Burke C, Merkel S, Tait AR. The revised FLACC observational pain tool: improved reliability and validity for pain assessment in children with cognitive impairment. Paediatric anaesthesia. 2006;16(3):258-65.

46. Hyman C, Snider LM, Majnemer A, Mazer B. Concurrent validity of the Neurobehavioural Assessment for Pre-term Infants (NAPI) at term age. Pediatric rehabilitation. 2005;8(3):225-34.

47. Solodiuk J, Curley MA. Pain assessment in nonverbal children with severe cognitive impairments: the Individualized Numeric Rating Scale (INRS). Journal of pediatric nursing. 2003;18(4):295-9.

48. Hunt A, Burne R. Medical and nursing problems of children with neurodegenerative disease. Palliative medicine. 1995;9(1):19-26.

49. Voepel-Lewis T, Merkel S, Tait AR, Trzcinka A, Malviya $\mathrm{S}$. The reliability and validity of the Face, Legs, Activity, Cry, Consolability observational tool as a measure of pain in children with cognitive impairment. Anesthesia and analgesia. 2002;95(5):1224-9, table of contents.

50. Breau LM, McGrath PJ, Camfield CS, Finley GA. Psychometric properties of the noncommunicating children's pain checklist-revised. Pain. 2002;99(1-2):349-57. 